\title{
Revegetation on abandoned salt ponds relieves the seasonal fluctuation of soil microbiomes
}

\author{
Huyen-Trang Tran ${ }^{1,2+}$, Hao-Chu Wang ${ }^{1 \dagger}$, Tsai-Wen Hsu ${ }^{3 \dagger}$, Rakesh Sarkar ${ }^{1}$, Chao-Li Huang ${ }^{4 *}$ (D) and Tzen-Yuh Chiang ${ }^{1 *}$
}

\begin{abstract}
Background: Salt pond restoration aims to recover the environmental damages that accumulated over the long history of salt production. Of the restoration strategies, phytoremediation that utilizes salt-tolerant plants and soil microorganisms to reduce the salt concentrations is believed to be environmentally-friendly. However, little is known about the change of bacterial community during salt pond restoration in the context of phytoremediation. In the present study, we used 165 metagenomics to compare seasonal changes of bacterial communities between the revegetated and barren salterns at Sicao, Taiwan.

Results: In both saltern types, Proteobacteria, Planctomycetes, Chloroflexi, and Bacteroidetes were predominant at the phylum level. In the revegetated salterns, the soil microbiomes displayed high species diversities and underwent a stepwise transition across seasons. In the barren salterns, the soil microbiomes fluctuated greatly, indicating that mangroves tended to stabilize the soil microorganism communities over the succession. Bacteria in the order Halanaerobiaceae and archaea in the family Halobacteriaceae that were adapted to high salinity exclusively occurred in the barren salterns. Among the 441 persistent operational taxonomic units detected in the revegetated salterns, 387 (87.5\%) were present as transient species in the barren salterns. Only 32 persistent bacteria were exclusively detected in the revegetated salterns. Possibly, salt-tolerant plants provided shelters for those new colonizers.
\end{abstract}

Conclusions: The collective data indicate that revegetation tended to stabilize the microbiome across seasons and enriched the microbial diversity in the salterns, especially species of Planctomycetes and Acidobacteria.

Keywords: Metagenomics, Salt pond restoration, Plant-microbe interaction, Seasonal fluctuation, Mangrove revegetation

\section{Background}

Ecological restoration and management have drawn the attention of conservation ecologists over the past decades [1]. Among the practices of ecological restoration, marine coastal restoration has received considerable attention [2]. Many coastal wetlands were ruined as a result of the development of salt pond industries. When these salt

\footnotetext{
*Correspondence: clhuang65535@mail.ncku.edu.tw;

tychiang@mail.ncku.edu.tw

†Huyen-Trang Tran, Hao-Chu Wang and Tsai-Wen Hsu contributed equally to this work.

${ }^{4}$ Institute of Tropical Plant Sciences, National Cheng Kung University, Tainan, Taiwan70101

'Department of Life Sciences, National Cheng Kung University, Tainan,

Taiwan70101

Full list of author information is available at the end of the article
}

ponds are no longer needed they are abandoned. The landscape is seriously disturbed and natural habitats are lost. To recover these ecological losses, an increasing number of salt pond restoration projects have been undertaken over last two decades globally $[3,4]$.

Among the strategies for salt pond restoration, cultivation of mangroves is an environmentally-friendly approach $[5,6]$. Artificial revegetation greatly decreases water and chemical usage in the soil improvement programs [7]. Mangroves improve the soil properties in saline environments shortly after their planting by increasing nutrient contents, enhancing water permeability, and reducing soluble salts [8-12]. The root systems secrete a wide diversity of root exudates that recruit various soil microorganisms [13]. Soil microorganisms are beneficial to the

(c) The Author(s). 2019 Open Access This article is distributed under the terms of the Creative Commons Attribution 4.0 International License (http://creativecommons.org/licenses/by/4.0/), which permits unrestricted use, distribution, and 
growth and health of plants, and help in stress alleviation, disease suppression, and nutrient acquisition [14-17]. Several microorganisms are able to promote plant growth in high salinity, including Planococcus maritimus CSSR02, Bacillus pumilus, and Fusarium culmorum FcRed1 [18-20]. Bacteria and fungi may help mangroves to adapt to the high salinity [7, 21]. Most of the beneficial effects are attributed to an interaction of the whole microbial community instead of any single species [22-25]. Therefore, understanding the interactions between soil microbiomes and mangroves in the salt pond restoration would provide insights into the application of revegetation in the ecological recovery.

The salt industry has been established in Taiwan since the past 300 years, with numerous salt ponds located along the southwest coast [4]. At Sicao in southern Taiwan ponds for salt treatments were established in 1919 and abandoned in 1996 [26]. The simultaneous restoration of salt ponds and preservation of the traditional method of salt production as a tourist attraction have involved the remediation of these abandoned ponds in the setting of an ecological park consisting of revegetated salterns and several barren salt ponds. Sicao has been selected as one of the "wetlands of international importance in Taiwan", because it is a major breeding site of the blackwinged stilt. A previous survey strongly correlated the faunal composition with mineral concentrations, particularly with salinity [27]. The salt concentration has remained high, fluctuating from $1.32-6.42 \%$ across seasons (http://wetland-tw.tcd.gov.tw/WetLandWeb/_download.php?id=2909\&flag=2). Salt-tolerant plants have been introduced to the salterns to expedite habitat restoration. These revegetated plants are typically mangroves, including Avicennia marina (Forsk.) Vierh, Kandelia candel (L.) Druce, Lumnitzera racemosa Willd, and Rhizophora mucronata Lam [26]. The contrasting landscapes provide an opportunity to explore the effects of replanted mangroves on the saltern microbiome.

We compared the soil microbiomes between revegetated and barren salterns at Sicao. In addition, as the compositions of microbial community are not constant across seasons [28-31], sampling was made in different seasons to monitor the dynamics of saltern microbiome. The study addressed the following questions:

1. Did the revegetation of mangroves change the microbial composition and the seasonal dynamics in the abandoned salterns?

2. What is the microbiome assembly in the barren salterns?

3. Are there any microbes associated with the revegetation? If yes, what are their roles?

4. From the view of soil microbiome, how did the mangroves contribute to the restoration of salt ponds at Sicao?

\section{Results}

\section{Changes of microbial communities across seasons}

The summaries of reads and distribution of operational taxonomic units (OTUs) in each sample are provided in Additional files 1 and 2. In total, 2,134,601 PE sequences were recovered from the raw data. After excluding singleton haplotypes, $1,131,078$ (52.99\%) PE reads remained. Of these reads, $60.4-68.1 \%$ were mapped to Greengenes OTUs. Of the 8085 OTUs that were detected, 55.7-96.5\% were assigned to bacteria, 2.2-33.8\% to archaea, $0.19-10.4 \%$ to chloroplasts, and $0.0-0.2 \%$ to mitochondria (see Additional file 1). After rarefaction to 8375 reads, 6760 microbial OTUs remained. These OTUs were assigned to 66 phyla (99.9\% reads), 157 classes (97.3\% reads), 252 orders (85.2\% reads), 283 families (59.6\% reads), 426 genera (22.5\% reads), and 148 species ( $2.3 \%$ reads). The bacterial community predominated in the Sicao samples, with abundance ranging from 62.4 to 97.8\% (average $=92.5 \%$ ), while archaea ranged from 2.3 to $37.6 \%$ (average $=7.5 \%$ ). Archaea tended to decrease from untreated (UN) to revegetated (RV), while bacteria tended to increase in RV (Mann-Whitney, $p=0.015$; see Additional file 3). At the phylum level, Proteobacteria, Planctomycetes, Chloroflexi, and Bacteroidetes were predominant both in UN and RV salt ponds across seasons (Fig. 1). Firmicutes and Euryarchaeota were present with a significantly higher abundance in UN compared with RV (Mann-Whitney, $p<0.02$; see Additional file 3). Firmicutes were prevalent in UN from May to November and markedly decreased in February, while Euryarchaeota were prevalent in UN from August to November. In contrast, Acidobacteria and Actinobacteria were more abundant with the presence of salt-tolerant plants (respective average was 11.75 and $3.57 \%$ ) than those without vegetation (4.31 and $1.68 \%$, respectively, MannWhitney, $p<0.015$; see Additional file 3$)$. In addition, the top five most abundant OTUs in UN were assigned to Halanaerobium (8.15\% with two OTUs), Nitrosopumilus (1.7\%, belonging to Archaea), Planctomycetes (1.5\%) and Rhodobacteraceae (1.3\%). The top five most abundant OTUs in RV were identified as members of Betaproteobacteria (2.8\% with two OTUs), Piscirickettsiaceae (1.2\%), Nitrosopumilus (1.1\%) and Pirellulaceae (1.1\%) (see Additional file 4).

We next used non-metric multidimensional scaling (NMDS) to visualize the differences in community composition (Bray-Curtis dissimilarity) between UN and RV at the phylum (Fig. 2) and OTU levels (see Additional file 5). No significant difference in composition was evident between UN and RV. After fitting the data of temperature and accumulated precipitation before sampling (Fig. 2), RV samples clustered near the center, while UN showed a more scattered pattern. These results suggested a closer association of samples in the RV 


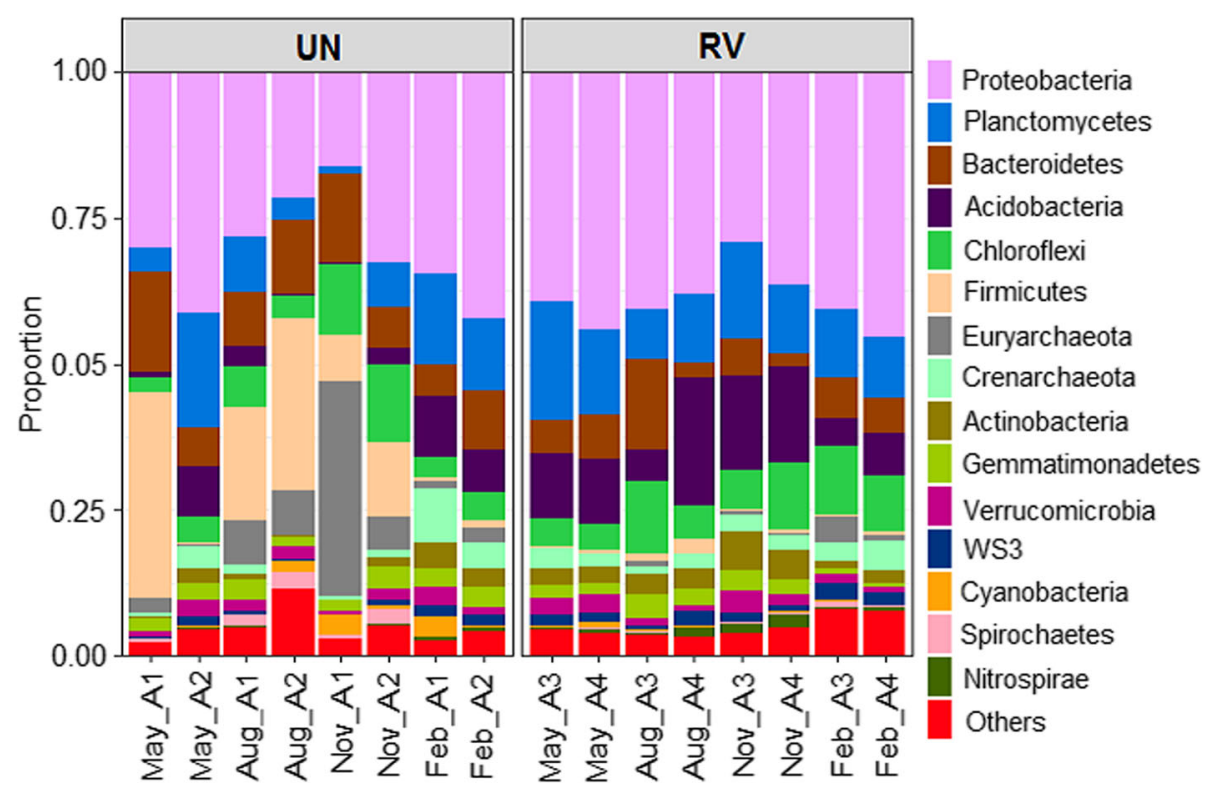

Fig. 1 Read distribution of sequences assigned to the phylum level in UN and RV across seasons. The taxa of low abundances $(<1 \%)$ are pooled as 'Others'

groups with each other than with UN samples. The RV community displayed a higher association with temperature and precipitation than the UN samples. In addition, the distribution of Firmicutes was likely associated with high temperatures and low precipitation, whereas Euryarchaeota tended to live in low temperature, high precipitation habitats. Pearman's correlation testing revealed that only Euryachaeota showed a significantly positive correlation with accumulated precipitation ( $p=0.02$; see Additional file 6).

In addition, we calculated the OTU richness (Chao1), Shannon index $\left(H^{\prime}\right)$, Simpson similarity (Sim), and Sørenson's similarity (Sør) for the saltern microbial communities across seasons. RV samples displayed no significant difference in OTU richness (Chao1) compared with UN (Mann-Whitney, $p>0.05$ ), while the soil microbiota displayed higher $H^{\prime}$ (Mann-Whitney, $p=0.009$; Fig. 3). From May 2013 to February 2014, the microbial diversity of UN tended to increase, while the trend was less obvious in RV. Both similarity indices plateaued when $70 \%$ of the OTUs (ranked by abundance) were included (Fig. 4). For Sør, the RV microbiome had a maximum value at 0.41 across seasons, and a lower value of 0.32 in UN. Likewise, Sim values were higher across seasons in RV than UN (0.34 vs. 0.26).

\section{OTU persistency and prevalence}

The persistence of saltern microbiome was examined to confirm the observation of the increased microbial diversity and stability in the salterns following revegetation. In total, 498 persistent OTUs (7.4\% of total OTUs) were detected from the four sampling sites. Of these, 81
(3.4\%) and 57 (1.6\%) were identified in sites A1 and A2 (UN), respectively, with 205 (5.5\%) and 344 (10\%) identified in sites A3 and A4 (RV), respectively (Fig. 5a). The observation of only 10 persistent OTUs in all sampling sites suggested that the seasonal persistency of soil bacteria fluctuated markedly in the salt evaporation ponds. The relative abundance of persistent OTUs also varied greatly across seasons. In UN, the persistent OTUs remained with low to moderate abundances of 10.8 to $22.8 \%$ across seasons. In RV, the prevalence was approximately $50 \%$ from May to November, but decreased dramatically to $22.6 \%$ in February, indicating contrasting trends between the presence and absence of salt-tolerant plants (Fig. 5b).

\section{Local habitat preferences}

Clamtest analyses were performed to identify the specialists in UN and RV. Of the 498 persistent OTUs, 40 OTUs $(8 \%)$ with extremely low frequencies were removed to avoid analytic noise. The remaining 329 OTUs were categorized as generalists $(66.1 \%)$, while 33 $(6.6 \%)$ and $96(19.3 \%)$ were identified as specialists in $\mathrm{UN}$ and RV, respectively (see Additional file 7A). In general, most of the persistent OTUs belonged to Proteobacteria, Planctomycetes, and Acidobacteria (Fig. 6), and the relative abundance of the generalists was stable in the UN and RV groups (see Additional file 7B). There was only slight increase in the abundance in the RV group compared to the UN group (37.4 and 27.9\%, respectively) (see Additional file 7B). The average relative abundance of specialist_UN and specialist_RV were 11.2 


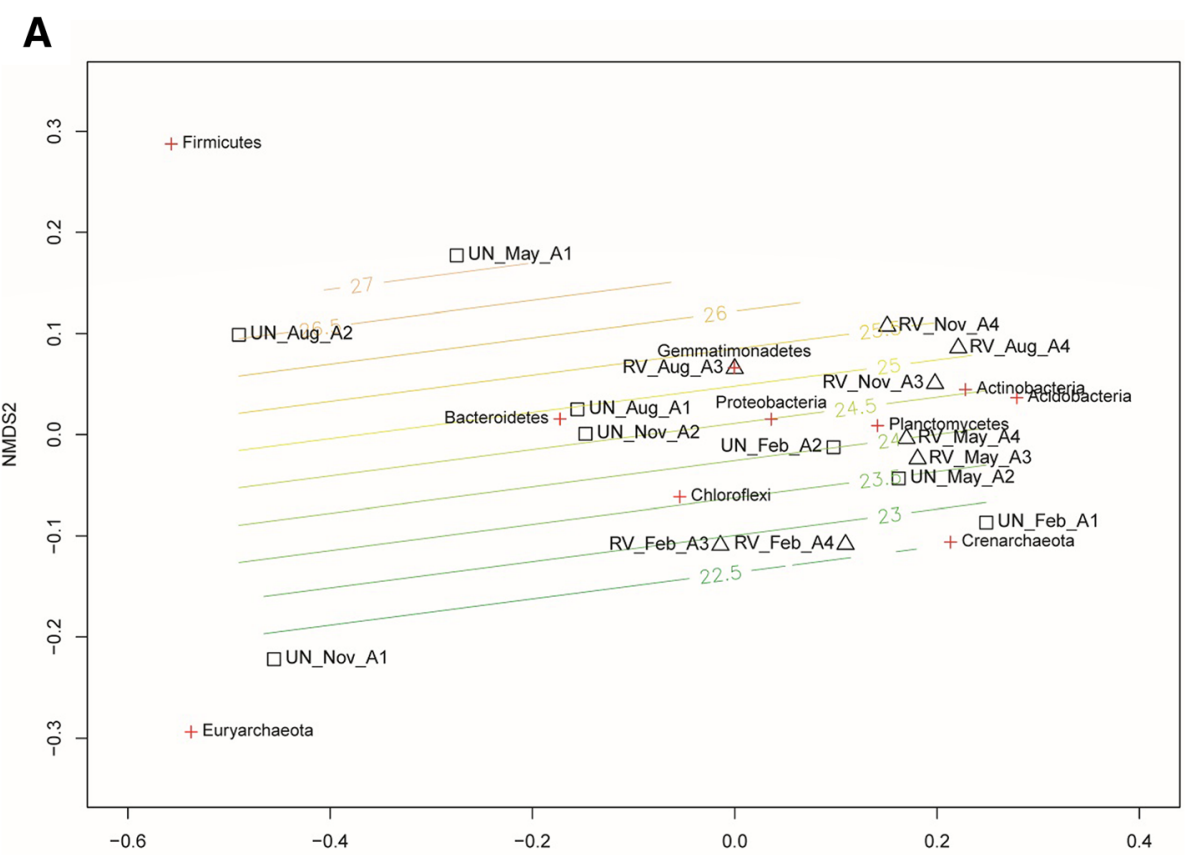

B

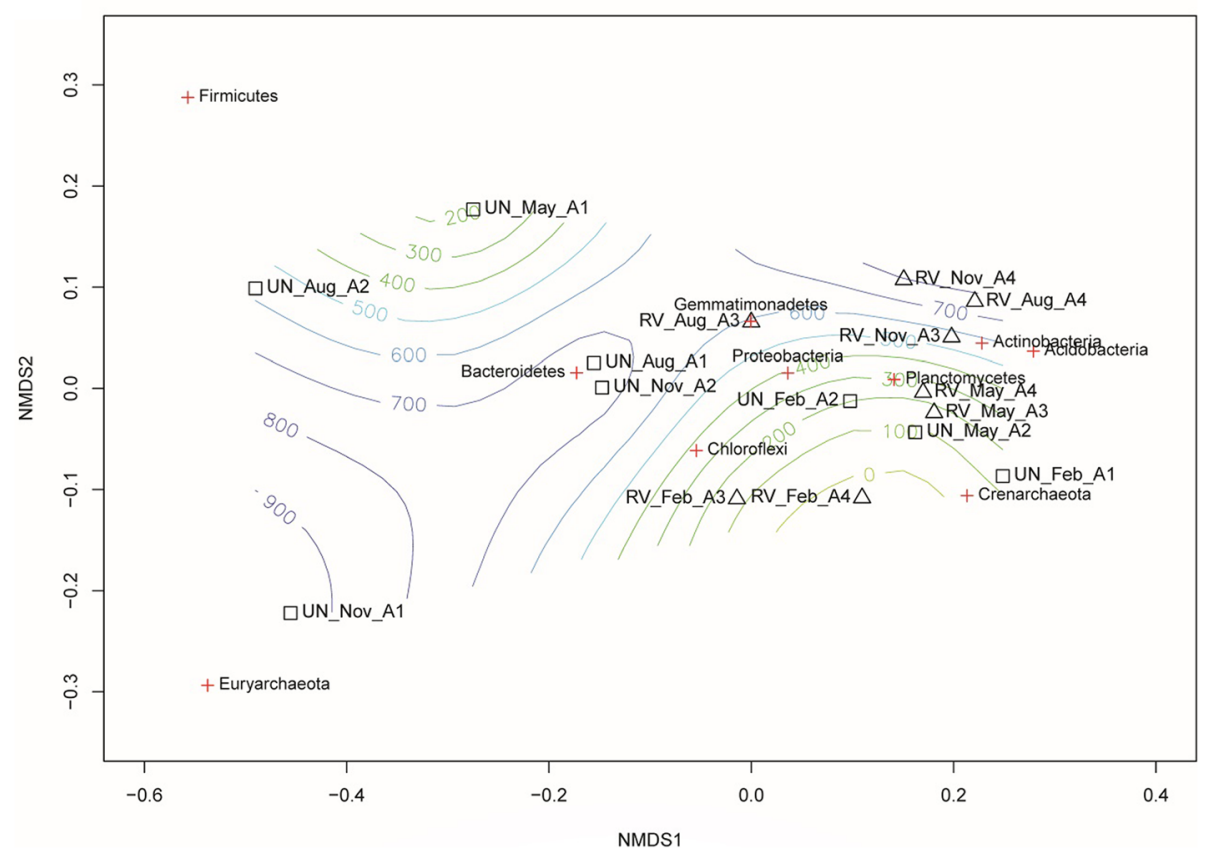

Fig. 2 Non-metric multidimensional scaling (NMDS) plots with fitted environmental gradients of temperature (a) and accumulated precipitation (b). NMDS plots were generated with Bray-Curtis distance (stress 0.08). Square and triangle respectively indicate untreated (UN) and revegetated (RV). Gradient colors represent temperature (a) or accumulated precipitation (b). The distribution of the top 10 phyla are indicated by red crosses

and $13.6 \%$, respectively (see Additional file $7 \mathrm{~B}$ ). When salttolerant plants were present, 387 (87.5\%) non-persistent OTUs in the barren salterns became persistent (Fig. 6). The average relative abundance of these OTUs was $16.4 \%$ in $\mathrm{UN}$ and $37.1 \%$ in RV (see Additional file 7C), suggesting that the prevalence also increased with the revegetation.
These microorganisms mostly belonged to Proteobacteria, Acidobacteria, Planctomycetes, and Chloroflexi (see Additional file 7C). Among these phyla, Acidobacteria and Planctomycetes OTUs tended to be persistent after the revegetation (hypergeometric tests: FDR-adjusted $p$-values of 0.0003 and 0.04, respectively; see Additional file 7C). These 

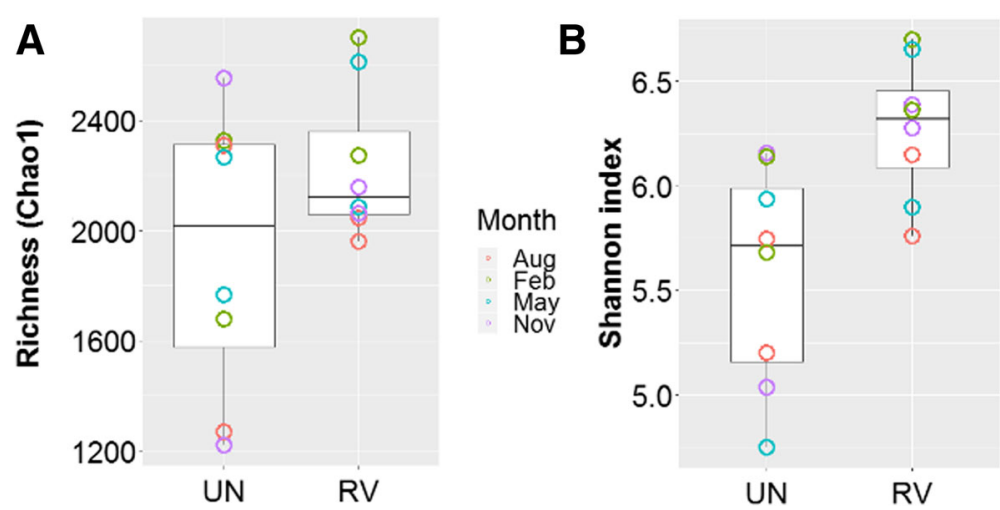

Fig. 3 Comparision of species diversity between untreated (UN) and revegetated (RV) sites. Double asterisks indicate significant difference between UN and RV (Mann-Whitney test, $p<0.01$ ). Each point is the Chao1 richness (a) or Shannon index (b) for the site at one sampling time

results also supported the view that revegetation in abandoned salterns likely increased the persistency (stability) of soil microbiome.

\section{Metabolic pathways deduced by PICRUSt}

Using the PICRUSt program, 6909 pathways were detected in the Kyoto Encyclopedia of Genes and Genomes Orthology database. These comprised 316 level 3 pathways. Most of the pathways were found in both the saltern types, while six pathways were exclusively detected in RV with very low relative abundance $(<0.0001 \%)$. To simplify the result, the top 30 pathways were visualized using a heat-map analysis (Fig. 7). Most RV samples were clustered, except for MayA3, suggesting that the saltern types could be distinguished by metagenomic functions. The pathways could be grouped into four clusters. Of these, Cluster 1 showed higher abundance in RV samples. The cluster was composed of "Two-component system", "Bacterial motility proteins", "Secretion system", "Chaperones and folding catalysts", "Carbon fixation", and "Amino sugar and nucleotide sugar metabolism". Among them, the abundance of the "Two-component system" was significantly higher in RV than that in UN (Mann-Whitney, $p=0.02$ ), implying some associations between this pathway and the revegetation.

\section{Discussion}

Salt evaporation ponds have usually been established by removing the native mangroves or other salt-tolerant plants from the coastal wetlands. Inevitably, after the devegetation, many ecological functions of wetlands were deleteriously affected, as revealed by the reductions in the diversity of fish, birds, invertebrates, and microorganisms

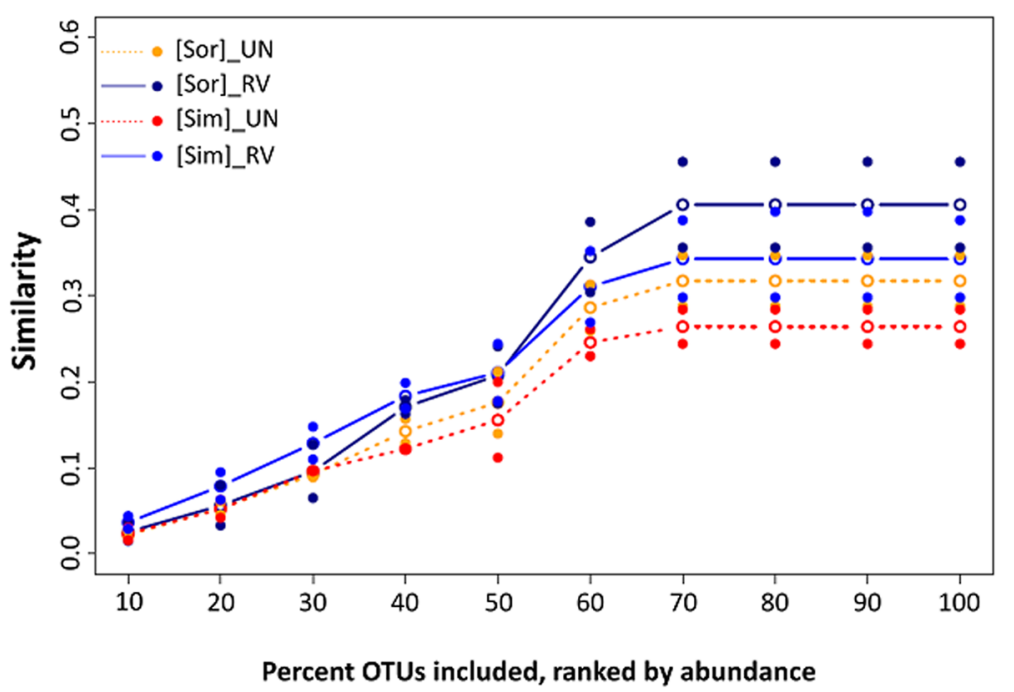

Fig. 4 Partition of similarity at different levels of prevalence. Measured as Sørenson's similarity ([Sør], orange and dark blue), and Simpson's similarity ([Sim], red and blue). Each point is the multivariate community similarity calculated for a time series from one site. The analysis was repeated at 10 cutoff levels to remove less prevalent OTUs. The line is an average across two sites in one group 

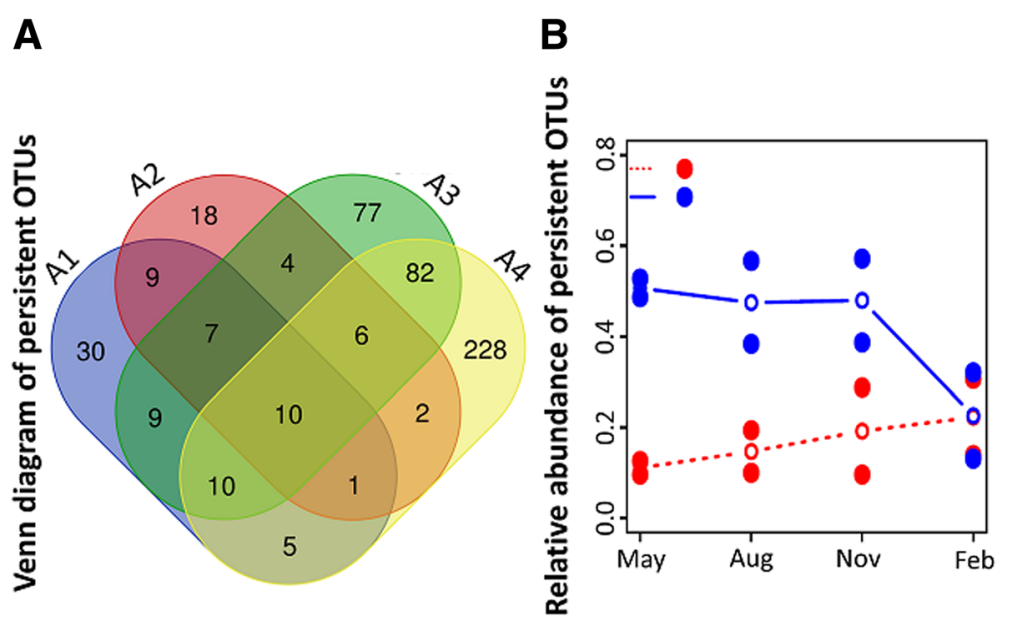

Fig. 5 Characteristic of OTU persistence and prevalence at the four sites. a Venn diagram shows the unique and shared persistent OTUs between four sites. b Relative abundance of persistent OTUs in two groups. Each point is a relative abundance of persistent OTUs at each site in one month. The line is an average of the two sites in one group. Red and blue respectively indicate untreated (UN) and revegetated (RV)

[32, 33]. Restoration of such damage by processes of natural succession usually requires centuries. To expedite habitat remediation, artificial revegetation involving the introduction of native plants is often practiced [34, 35]. The salt pond system at Sicao is a perfect example.

Evaluating soil health by investigating the microbial composition in the soil ecosystem has been suggested [36]. In the present study, metagenomic analyses revealed a microbial community with higher species diversity in the revegetated salterns (Fig. 3b). A likely scenario for the increased diversity is that the revegetation may have created novel niches for immigrants from neighboring fields, as indicated by the existence of unique microorganisms in the revegetated salterns (belonging mainly to Proteobacteria,

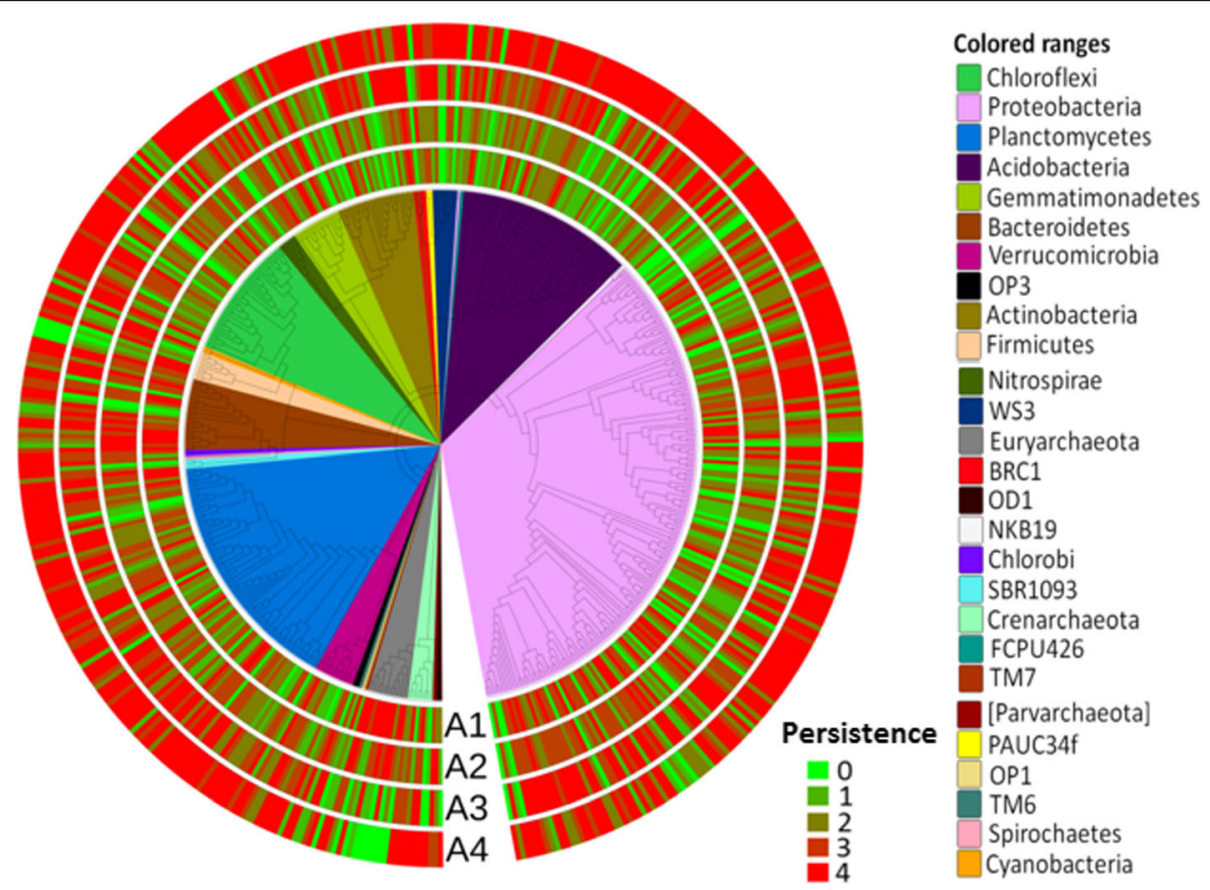

Fig. 6 Taxonomy and occurrence of 498 persistent OTUs across each sample. The maximum likelihood tree of the bacterial domain was built based on the alignment of 498 persistent OTUs. Phyla are distinguished by branch color. The outer rings represent the status of OTU persistency in each site. Heat-map colors from green to red indicate for OTU occurrence of persistent OTUs across season in each site. The order is A1 to A4 from inside to outside 


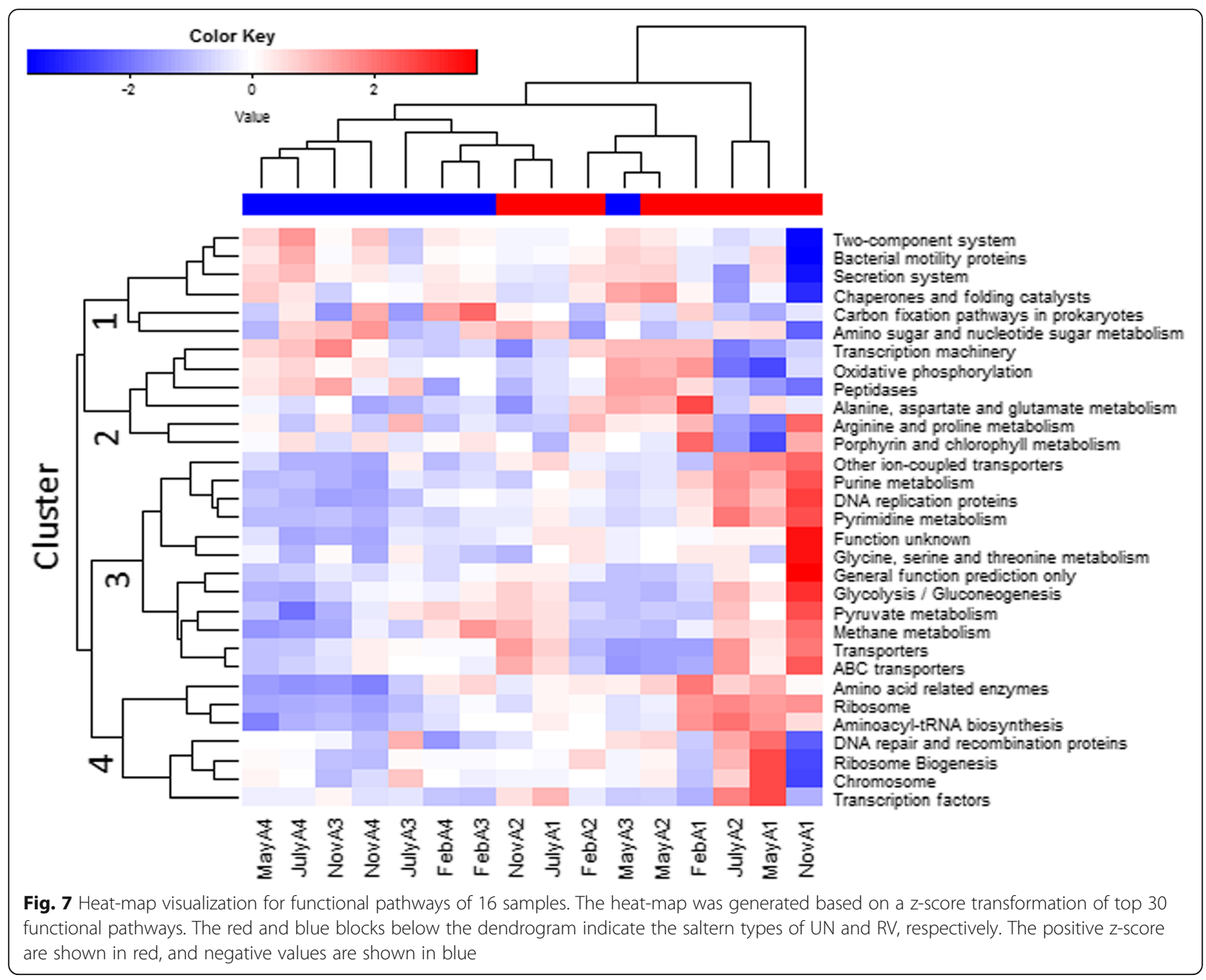

Planctomyces, Bacteroidetes, and Acidobacteria; see Additional file 9). The metagenomic data indicated that over the course of succession following revegetation, 1639 and 2531 OTUs might have been lost and gained, respectively. The net difference of 896 OTUs was likely attributable to the habitat recovery with the presence of salttolerant plants. In addition, the increasing number of specialists in the revegetated salterns also suggested that more ecological niches were developed by phytoremediation. During the process, plants are able to release a wide array of root exudates that mediate various interactions with soil microorganisms, including an expansion of available carbon sources [37]. A trend of increased diversity was also evident for bacteria after the revegetation in terms of the species composition, especially those belonging to Acidobacteria, Actinobacteria, Proteobacteria, Chloroflexi, and Planctomycetes (see Additional file 3). Additionally, the nourishing effect by vegetation was more pronounced for bacteria, as the number of archaeal species decreased by 59 and the average relative abundance of archaea decreased from 11.0 to $4.1 \%$ after revegetation (see Additional file 3). This also indicates that many archaea may survive in severe environments. At the phylum level, the reduction of archaea was due to the loss of Euryarchaeota taxa, while Crenarchaeota were stable. The most prevalent Euryarchaeota in the Sicao salterns belonged to the Halobacteriaceae. They are highly halophilic, adapt to high osmotic pressure, and require over $100-150 \mathrm{~g} / \mathrm{L}$ salt for survival [38]. Several salt-tolerant plants are able to take up excess ions from soil and relieve the interference to the roots via secretion or accumulation. For example, the mangrove Luminitzera can store excess salt in the succulent leaves, while Avicennia utilizes salt glands to eliminate the salts $[39,40]$. Such mechanisms enable the plants to reduce the salinity in neighboring soil, as revealed by a previous study showing that the revegetation on saline soil reduces salinity up to 10 -fold [41]. These results imply that the return of plants transforms the environment to a state that is detrimental to halophilic prokaryotes. Similar to Euryarchaeota, 
Firmicutes displayed a reduction following the revegetation. The most predominant Firmicutes in the barren salterns belonged to Halanaerobiaceae, a moderately halophilic family that thrives under high temperatures $\left(34-40{ }^{\circ} \mathrm{C}\right)$ and salinity (approximately $\left.10 \%\right)$ [42]. Accordingly, the decline in halophilic species resulted in the corresponding reductions in the abundance of Firmicutes and Euryarchaeota.

Firmicutes also displayed pronounced seasonal variation in the barren salterns. The relative abundance was higher in May and August (19.5 and 16.0\%, respectively), lower in November $(8.6 \%)$, and extremely low $(<1 \%)$ in February; this displayed a positive correlation between the relative abundance and temperatures (see Additional file 6). Higher temperatures may trigger salt tolerance of the microorganisms [43]. Accordingly, the low temperatures in February $\left(<20^{\circ} \mathrm{C}\right)$ limited growth. Euryarchaeota also displayed a similar pattern; they were abundant in August and November, and less abundant in February and May. This is likely due to the accumulating precipitation (see Additional file 5). Collectively, in response to the climate changes, the microbial flora widely fluctuated in the saltern ecological systems.

Temperature and precipitation may have critical roles in changing the microbial composition across seasons [29-31, 44]. As mentioned above, Firmicutes might be influenced by temperature and Euryarchaeota by precipitation. In addition, the nature of the salterns (barren versus revegetated) could be influential (Fig. 2). The NMDS analysis revealed a correlation of the saltern microbiome with the accumulated precipitation. In the rainy months of August and November, the microbial communities of the barren and revegetated salterns were different and were located at the left and upper right regions of the NMDS representation, respectively. In the dry seasons, there was less of a difference between two saltern types, except for UN_May_A1, which clustered in the lower right region (Fig. 2b). This pattern suggested that the influence of vegetation is more pronounced during the rainy seasons. In Taiwan, periods of accentuated rainfall are coupled with severe weather, including typhoons and the 'plum rains' of late spring and early summer. These natural forces are expected to have great impacts on the composition of the soil microbiome [45], as revealed by the dynamics of saltern microflora in the rainy seasons. Interestingly, unlike the scattered pattern of the UN samples, the RV microbiome exhibited stepwise changes along an upward trajectory with the increasing accumulation of precipitation (Fig. 2b). This finding suggests that plants may have resulted in the stable transition of the soil microbiome across seasons, increasing the ecological stability of saltern environments. A similar community structure was also found in the cool and dry month of February, which likely reflected the stable climate in winter. The NMDS analysis further revealed a stable and stepwise transition of the microbiome in the revegetated salterns across seasons (Fig. 2). Sørenson and Simpson similarity indices also revealed a higher stability in the revegetated salterns, as the soil microbiome was less variable than that of the barren salterns (Fig. 4). Based on the the microbial composition (Figs. 5 and 6), the stable transition in revegetated salterns was likely associated with the increasing number of persistent microbes, as the persistence of species is an intuitive indicator of ecological stability [46]. In the revegetated salterns, 441 persistent microorganisms were detected, which was approximately 4-times the number of persistent microorganisms in the barren salterns (111 OTUs). Persistent microorganisms accounted for up to $60 \%$ of the soil microbiome after revegetation, while the barren salterns were predominated by non-persistent microorganisms across seasons. Apparently, ecological stability was strengthened by revegetation in the salterns. There are two possible contributors to the increase in the number of persistent microbes-new colonization events and the microbial conversion from non-persistent to persistent. More than $85 \%$ of the persistent microbes in the mangrove salterns were also detected as non-persistent microbes in the barren salterns, whereas $<10 \%$ of the persistent microbes were derived from colonization events. Most of the persistent microorganisms (78\%) did not display preferences to barren or mangrove salterns. These results indicate that the colonization events may not be the main reason for the recruitment of persistent microbes. Alternatively, plants likely stabilized the resident soil microorganisms in the salterns by alleviating the influences of climate changes. Root exudates contain abundant photosynthetic metabolites, including simple sugars and amino acids [13, 47, 48]. The expansion of organic matter after revegetation in the saline soil has been reported [7, 41, 49]. During bioremediation, the increased available resources would provide better nourishment for soil microorganisms that had survived the unfavorable conditions [50]. This might be one of the reasons that existing microbes were more likely to become persistent upon the introduction of salt-tolerant plants. Contrastingly, the PICRUSt analysis suggested that the revegetated saltern is significantly enriched of the bacterial function of "Two-Component System" (TCS) (see Additional file 8). The TCS is composed of sensor and transducer components that can respond to various environmental changes [51]. The system links prokaryotic cells with their environments [52]. The genomic abundance of TCS is associated with trophic levels, as indicated by the greater number of TCS related genes in prokaryotic copiotrophs in comparison to oligotrophs [52]. As copiotrophs thrive in nutrient-rich environments, the 
metabolic analysis suggests that revegetation improves the growth condition for soil microorganisms.

Among the microbes that showed enhanced persistence after the revegetation, Acidobacteria and Planctomycetes were particularly favored by the presence of mangroves (see Additional file $7 \mathrm{C}$ ). Acidobacteria are a common component of rhizosphere communities [53] and important contributors to the microbial assembly in aquatic and terrestrial ecosystems [54]. Acidobacteria are likely to possess active metabolisms that promote plant growth [55-57]. Plant diversity is in turn a critical factor in shaping their community structure, probably via providing carbon sources to attract specific Acidobacteria toward the root systems [58]. Likewise, the Planctomycetes are reportedly associated with mangroves and seagrasses [59-61]. Halophytes are able to alter the distribution of bacteria, especially those belonging to the Planctomycetes [62]. These bacteria are involved in the nitrogen cycle, including the anammox bacteria with anaerobic oxidation of soil ammonia in saline sediments [62]. On the other hand, Actinobacteria were also enriched in revegetated salterns, especially for the order Acidimicrobiales (see Additional files 3 and 10). Acidimicrobiales have been reported as predominant microbes in the rhizosphere of salt-tolerant plants, including Agave, Halimione, and Sarcocornia [63, 64]. However, as only a few species in this order have been isolated and studied [65], their interaction with plants still requires more research.

The collective findings indicate that revegetation is the beginning of the restoration toward a well-functioning wetland. The bacteria may be involved in the growth promotion of salt-tolerant plants as well as the processes of the nitrogen cycle.

\section{Conclusions}

Salt-tolerant plants tend to stabilize the soil microbiome of the Sicao salt ponds. These plants may help the nonpersistent microbes thrive during climate transition. As the number of persistent microbes increased, the ecological stability of mangrove salterns improved because of the increasing diversity of the soil microbiome. With revegetation, the numbers of Firmicutes and Euryarchaeota markedly declined, while Acidobacteria and Planctomycetes thrived across seasons. Such plant-microbe interactions may facilitate the succession processes in barren salterns and restore the ecological functions of a coastal wetland.

\section{Methods}

\section{Site descriptions and sampling}

This study was conducted in a national ecological park with several salt evaporation ponds at Sicao, Tainan, Taiwan $\left(23.026^{\circ} \mathrm{N}, 120.141^{\circ} \mathrm{E}\right)$. Four experimental sites
(A1-A4) were set. Two sites had been revegetated with salt-tolerant plants [Kandelia candel (L.) Druce, Lumnitzera racemosa Willd, Rhizophora mucronata Lam, and Avicennia marina (Forsk) Vierh, Phragmites australis]. The other two sites had been untreated and were used as controls (see Additional file 11). Accordingly, the experimental sites were classified as untreated saltern (UN) and saltern with revegetation (RV).

In Tainan, the rainy season generally starts in April and ends in September (see Additional file 12). Accordingly, we collected soil samples from the saltern fields in May, August, November, and February in 2013 and 2014 to assess the microbial dynamics across rainy and dry seasons. Each sample was a homogeneous mixture of three sub-samples from the solid soil surface in the same site (approximately $20 \mathrm{~cm}$ in depth). Soil samples were stored on ice and transported to the laboratory immediately. In total, 16 samples were obtained.

\section{DNA extraction and PCR}

Soil DNA was isolated with the PowerSoil ${ }^{\circ}$ DNA Isolation Kit (MO BIO Laboratories, Inc., USA). A 789F primer (5' TAG ATA CCC SSG TAG TCC - $3^{\prime}$ ) and 1053R nucleotide reverse primer (5' - CTG ACG RCR GCC ATG C-3') were used to amplify the target V4-V6 region of 16S-rRNA. The primer pair was chosen because of its wide coverage of bacterial lineages $[66,67]$. For each sample, PCR was performed in eight to 12 tubes. The reaction volume was $50 \mu \mathrm{L}$. Each reaction volume consisted of $1 \times \mathrm{Taq} 2 \mathrm{x}$ Master Mix Red (Ampliqon, Denmark), $0.1 \mu \mathrm{M}$ of each primer, and $10 \mathrm{ng}$ template DNA. PCR conditions were $95^{\circ} \mathrm{C}$ for $5 \mathrm{~min}$; 27 cycles of $95^{\circ} \mathrm{C}$ for $30 \mathrm{~s}, 50^{\circ} \mathrm{C}$ for $30 \mathrm{~s}, 72^{\circ} \mathrm{C}$ for $50 \mathrm{~s}$, and a final extension at $72{ }^{\circ} \mathrm{C}$ for $10 \mathrm{~min}$. PCR products were visualized using $1.2 \%$ agarose gel electrophoresis and purified using a Gel/PCR DNA extraction Kit (Geneaid, Taiwan). The purified PCR products were precipitated and concentrated with isopropanol. The DNA concentration was quantified using a Qubit 2.0 Fluorometer (Invitrogen, USA).

\section{Metagenomic sequencing and analysis OTU generation and rarefied OTU table}

PCR products were sequenced using an Illumina MiSeq with 250-bp paired-end sequencing. All raw sequence data has been deposited in the GenBank Sequence Read Archive database (http://www.ncbi.nlm.nih.gov/sra/) under the accession number SRP134270. Using a Perlscripted pipeline, raw reads were quality (trimmed) filtered (average quality value $>=20$ and length $>=100$ bp). After quality filtering, non-paired reads were discarded, and paired reads were assembled according to the overlapping sequences. The primer sequences were trimmed from the assembled sequences, haplotypes were generated by merging identical sequences, and the 
abundances were determined. Singleton haplotypes were discarded due to possible sequencing errors. Finally, OTUs were identified by clustering haplotypes with the OTUs of the Greengenes database (August 2013 version) at $97 \%$ sequence identity using the 'pick_closed_reference_otu.py' function implemented in the QIIME software package 1.9.0 [68]. Mitochondrion, chloroplast, and singleton OTUs were excluded before further analysis for bacteria and archaea. The "rrarefy" function in the vegan v.2.4-4 package [69] was used to rarefy all samples to 8375 reads (corresponding to the lowest number of microbial reads detected in NovA3). All community analyses were based on the rarefied results.

\section{Community analysis}

The vegan package was also used to estimate OTUs richness (Chao1), Shannon index, Simpson similarity, Sørenson similarity, and NMDS (meta-MDS function) based on Bray-Curtis distance. The "ggscatter" function in the ggpubr package was used for Pearson correlation coefficient analysis between the abundance of Firmicutes and Euryarchaeota with temperature and accumulated precipitation before sampling [70]. The OTUs that occurred at all time points in a sampling site were defined as persistent OTUs, while the remainders were considered non-persistent OTUs. The distributions of persistent OTUs were visualized with an online Venn diagram tool (http://bioinformatics.psb.ugent.be/webtools/Venn/). Functional pathway profiles from $16 \mathrm{~S}$ metagenomics were predicted by PICRUSt version 1.1.3. [71]. Heat-map for functional pathways was generated in $\mathrm{R}$ with a $\mathrm{z}$-score transformation.

The clamtest function of the vegan package was used to classify specialist and generalist with and without the presence of replanted salt-tolerant plants. All parameters for clamtest were set as default values with the "supermajority" rule [72].To detect the phyla that were enriched in the group of persistent generalists, a hypergeometric test was used. The $p$-values were corrected with a false discovery rate of 0.05 . A statistically significant result was one where the corrected p-value was $<0.05$. A maximum likelihood tree based on 428 persistent generalist OTUs was generated by MEGA7 [73]. The tree was visualized with Interactive Tree Of Life v.3.0 [74].

\section{Additional files}

Additional file 1: Table S1. Summary of sequencing reads from 789F1053R marker. (XLSX 14 kb)

Additional file 2: Table S2. Summary of haplotypes and Operational Taxonomical Unit (OTU) numbers detected using 789F-1053R markers. (XLSX $15 \mathrm{~kb})$

Additional file 3: Figure S1. Box-plots of relative abundance of the two kingdoms and the top 10 phyla between UN and RV. Asterisks denote statistically significant difference evaluated by Mann-Whitney test between UN and RV. ${ }^{*}, p$-value $<=0.05$, and ${ }^{* *}, p$-value $<0.01$. (TIF $1657 \mathrm{~kb}$ )
Additional file 4: Figure S2. Distribution of taxon abundances among OTUs (with singletons removed) detected in (A) UN and (B) RV. Top five OTUs in relative abundance with taxa assignation in (C) UN and (D) RV. (TIFF $52 \mathrm{~kb}$ )

Additional file 5: Figure S3. NMDS (non-metric multidimensional scaling) plots of all 16 samples based on Bray-Curtis distance at OTUs level (stress 0.09). (TIFF $66 \mathrm{~kb}$ )

Additional file 6: Figure S4. Pearson correlation coefficient analysis of temperature and accumulated precipitation with (A) Firmicutes and (B) Euryarchaeota. Red and blue lines present linear regression of UN and RV samples, respectively. Red and blue shades denote for the confidence intervals at 95\%. (TIFF $89 \mathrm{~kb}$ )

Additional file 7: Figure S5. Local habitat preferences. (A) Habitat preferences of the persistent OTUs. Based on the clamtest, each OTU was classified as specialists in UN (red squares), specialists in RV (green diamonds), "too rare" (blue triangles), or generalist (black circles). B). Distribution of habitat preference of the persistent OTUs in each site. C). Phylum distribution of the 387 OTUs that are persistent in RV but nonpersistent in UN. The asterisks indicate significant enrichment of the number of persistent OTU for the phyla at RV (hypergeometric test, $p=0.04$ ). (TIFF $137 \mathrm{~kb}$ )

Additional file 8: Figure S6. Abundance comparison for the six pathways of cluster 1 between UN and RV. The asterisk (*) represents a statistical significance. (TIFF $38 \mathrm{~kb}$ )

Additional file 9: Figure S7. Top five phyla of unique microorganisms in RV. (TIFF $25 \mathrm{~kb}$ )

Additional file 10: Figure S8. Relative abundance of order Acidimicrobiales in phylum Actinobacteria. A). OTUs number. B). Reads. (TIFF $31 \mathrm{~kb}$ )

Additional file 11: Figure S9. Information for sampling sites. Mapping of sampling was drawn based on the google map data 2018. Photos of sampling sites were provides along with sites. (TIFF $373 \mathrm{~kb}$ )

Additional file 12: Figure S10. Average monthly of (A) temperature and (B) precipitation of Tainan during 1990-2014. (TIFF 32 kb)

\section{Abbreviations}

DNA: Deoxyribonucleic acid; NMDS: Non-metric multidimensional scaling; OTUs: Operational Taxonomic Unit; PCR: Polymerase chain reaction; PE: Paired-end sequencing; RV: The saltern with revegetation; SRA: Sequence Read Archive; UN: The untreated saltern

\section{Acknowledgments}

We thank National Cheng Kung University for the supporting grant.

\section{Authors' contributions}

$\mathrm{CLH}$ and TYC designed the experiments. The experiments were performed by HCW and RS. The data analyses were done by HTT, HCW, TWH, and CLH. The manuscript was drafted by HTT and revised by CLH and TYC. The final version was approved by all authors.

\section{Funding}

This work was supported by the Aim for the Top University Project of National Cheng Kung University.

\section{Availability of data and materials}

The raw sequencing reads is deposited in GenBank's Sequence Read Archive (SRA) database (http://www.ncbi.nlm.nih.gov/sra/) under the accession number SRP134270.

Ethics approval and consent to participate

Not applicable.

\section{Consent for publication}

Not applicable.

\section{Competing interests}

The authors declare that they have no competing interests. 


\section{Author details}

'Department of Life Sciences, National Cheng Kung University, Tainan, Taiwan70101. '2Department of Biology, Institute of Natural Science Education, Vinh University, Vinh, Nghe An 461010, Vietnam. ${ }^{3}$ Taiwan Endemic Species Research Institute, Nantou, Taiwan55244. Institute of Tropical Plant Sciences, National Cheng Kung University, Tainan, Taiwan70101.

\section{Received: 16 May 2018 Accepted: 31 May 2019}

\section{Published online: 11 June 2019}

\section{References}

1. Falk DA, Palmer MA, Zedler JB. Foundations of Restoration Ecology. USA: Island Press; 2006.

2. Bayraktarov E, Saunders MI, Abdullah S, Mills M, Beher J, Possingham HP, Mumby PJ, Lovelock CE. The cost and feasibility of marine coastal restoration. Ecol Appl. 2016;264:1055-74.

3. Siegel SW, Bachand PAM. Feasibility analysis of south bay salt pond restoration, San Francisco estuary, California. USA: Wetlands and Water Resources; 2002.

4. Zhang FM, Fang JY. Salt industry in Taiwan (in Chinese). Taiwan: Walkers Cultural Enterprises; 2008.

5. Qadir M, Oster J. Vegetative bioremediation of calcareous sodic soils: history, mechanisms, and evaluation. Irrigation Sci. 2002;21:91-01.

6. Qadir M, Oster JD. Crop and irrigation management strategies for salinesodic soils and waters aimed at environmentally sustainable agriculture. Sci Total Environ. 2003:323:1-19.

7. Arora S, Singh AK, Singh YP. Bioremediation of salt affected soils: an Indian perspective. Switzerland: Springer International Publishing AG; 2017.

8. Mishra A, Sharma SD, Khan GH. Improvement in physical and chemical properties of sodic soil by 3,6 and 9 years old plantation of Eucalyptus tereticornis: bio-rejuvenation of sodic soil. Forest Ecol Manag. 2003;184:115-24.

9. Nosetto MD, Jobbágy EG, Tóth T, Di-Bella CM. The effects of tree establishment on water and salt dynamics in naturally salt-affected grasslands. Oecologia. 2007;152:695-05.

10. Sharma DK, Chaudhari SK. Agronomic research in salt affected soils of India: an overview. Indian J Agron. 2012;57:175-85.

11. Sharma DK, Singh A. Salinity research in India: achievements, challenges and future prospects. Water Energy Intl. 2015;58:35-45.

12. Singh $G$, Singh NT, Abrol IP. Agroforestry techniques for the rehabilitation of degraded salt-affected lands in India. Land Degrad Dev. 1994;5:223-42.

13. Badri DV, Weir TL, Van-Der-Lelie D, Vivanco JM. Rhizosphere chemical dialogues: plant-microbe interactions. Curr Opin Biotech. 2009;20:642-50.

14. Dimkpa C, Weinand T, Asch F. Plant-rhizobacteria interactions alleviate abiotic stress conditions. Plant Cell Environ. 2009;32:1682-94.

15. Maya S, Tirosh T, Glick BR. Plant growth-promoting bacteria confer resistance in tomato plants to salt stress. Plant Physiol Bioch. 2004;42:565-42.

16. Mendes R, Kruijt M, De-Bruijn I, Dekkers E, Van-Der-Voort M, Schneider JH, et al. Deciphering the rhizosphere microbiome for disease-suppressive bacteria. Science. 2011;332:1097-00.

17. Morrissey JP, Dow JM, Mark GL, O'Gara F. Are microbes at the root of a solution to world food production? EMBO Rep. 2004;5:922-6.

18. Arora S, Vanza MJ, Mehta R, Bhuva C, Patel PN. Halophilic microbes for bio -remediation of salt affected soils. Afr J Microbiol Res. 2014;8:3070-8.

19. Kannan R, Damodaran T, Umamaheswari S. Sodicity tolerant polyembryonic mango root stock plants: a putative role of endophytic bacteria. Afr J Biotechnol. 2015;14:350-9.

20. Ruzzi M, Aroca R. Plant growth-promoting rhizobacteria act as biostimulants in horticulture. Sci Hortic. 2015:196:124-34.

21. Yuan Z, Druzhinina IS, Labbé J, Redman R, Qin Y, Rodriguez R, et al. Specialized microbiome of a halophyte and its role in helping non-host plants to withstand salinity. Sci Rep. 2016;6:32467.

22. Bulgarelli D, Schlaeppi K, Spaepen S, Ver-Loren-Van TE, Schulze LP. Structure and functions of the bacterial microbiota of plants. Annu Rev Plant Biol. 2013;64:807-38.

23. Friesen ML, Porter SS, Stark SC, von Wettberg EJ, Sachs JL, MartinezRomero E. Microbially mediated plant functional traits. Annu Rev Ecol Evol S. 2011;42:23-46.

24. Lebeis SL, Rott M, Dangl JL, Schulze LP. 28th new Phytologist symposium: culturing a plant microbiome community at the cross-Rhodes. New Phytol. 2012;196:341-4.
25. Vandenkoornhuyse P, Quaiser A, Duhamel M, Le-Van A, Dufresne A. The importance of the microbiome of the plant holobiont. New Phytol. 2015; 206:1196-06.

26. Yang Y. Restoration Strategies of the Abandoned Salt Pond - a case study at Taijiang National Park in Taiwan. In: Collaboration among government, market, and society: Forging partnerships and encouraging competition; 2013. p. 1-20. http://www.umdcipe.org/conferences/ GovernmentCollaborationShanghai/Submitted_Papers/Yang_Y_Paper.pdf.

27. Liao MH, Su HS, Chen WR, Lin YJ, Wang MY, Ueng YT. The structure equation models of water quality and aquatic animals during habitat restoration period in Sicao conservation area. Wetlands Taiwan. 2005;58:53-9.

28. Bárcenas-Moreno G, Gómez-Brandón M, Rousk J, Bååth E. Adaptation of soil microbial communities to temperature: comparison of fungi and bacteria in a laboratory experiment. Glob Change Biol. 2009;15:2950-7.

29. Gordon H, Haygarth PM, Bardgett RD. Drying and wetting effects on soil microbial community composition and nutrient leaching. Soil Biol Biochem. 2008:40:302-11.

30. Jones AC, Liao TSV, Najar FZ, Roe BA, Hambright KD, Caron DA. Seasonality and disturbance: annual pattern and response of the bacterial and microbial eukaryotic assemblages in a freshwater ecosystem. Environ Microbiol. 2013;15:2557-72.

31. Tinta T, Vojvoda J, Mozetič P, Talaber I, Vodopivec M, Malfatti F, Turk V. Bacterial community shift is induced by dynamic environmental parameters in a changing coastal ecosystem (northern Adriatic, northeastern Mediterranean Sea) - a 2-year time-series study. Environ Microbiol. 2015;17:3581-96.

32. Gómez-Acata ES, Valencia-Becerril I, Valenzuela-Encinas C, VelásquezRodríguez AS, Navarro-Noya YE, Montoya-Ciriaco N, et al. Deforestation and cultivation with maize (Zea mays L.) has a profound effect on the bacterial community structure in soil. Land Degrad Dev. 2014;27:1122-30.

33. Uzarski DG, Burton TM, Kolar RE, Cooper MJ. The ecological impacts of fragmentation and vegetation removal in Lake Huron coastal wetlands. Aquat Ecosyst Health Manag. 2009;12:45-62.

34. Steven DD, Sharitz RR, Singer JH, Barton CD. Testing a passive revegetation approach for restoring coastal plain depression wetlands. Restor Ecol. 2006;14:452-60.

35. Moreno-Mateos D, Meli P, Vara-Rodnguez Ml, Aronson J. Ecosystem response to interventions: lessons from restored and created wetland ecosystems. J Appl Ecol. 2015;52:1528-37.

36. Schlotera M, Dillyb O, Muncha JC. Indicators for evaluating soil quality. Agric Ecosyst Environ. 2003;98:255-62.

37. Sun TR, Cang L, Wang QY, Zhou DM, Cheng JM, Xu H. Roles of abiotic losses, microbes, plant roots, and root exudates on phytoremediation of PAHs in a barren soil. J Hazard Mater. 2010;176:919-25.

38. Oren A. Microbial life at high salt concentrations: phylogenetic and metabolic diversity. Saline Syst. 2008;4:2.

39. Parida AK, Jha B. Salt tolerance mechanisms in mangroves: a review. Trees 2010;24:199-217.

40. Tomlinson PB. The botany of mangroves. Cambridge: Cambridge University Press; 1986.

41. Hopkins DG, Sweeney MD, Kirby DR, Richardson JL. Effects of revegetation on surficial soil salinity in Panspot soils. J Range Manage. 1991;44:215-20.

42. Oren A. The order Halanaerobiales, and the families Halanaerobiaceae and Halobacteroidaceae. In: Rosenberg E, DeLong EF, Lory S, Stackebrandt E, Thompson F, (eds). The Prokaryotes. Berlin: Springer; 2014. p. 153-77.

43. Ibekwe AM, Ors S, Ferreira JFS, Liu X, Suarez DL. Seasonal induced changes in spinach rhizosphere microbial community structure with varying salinity and drought. Sci Total Environ. 2017;579:1485-95.

44. Singh BK, Bardgett RD, Smith P, Reay DS. Microorganisms and climate change: terrestrial feedbacks and mitigation options. Nat Rev Microb. 2010;8:779-90.

45. Mace OG, Steinauer K, Jousset A, Eisenhauer N, Scheu S. Flood-induced changes in soil microbial functions as modified by plant diversity. PLoS One. 2016;11:e0166349.

46. May R, McLean A. Theoretical ecology: principles and applications. UK: Oxford University Press; 2007

47. Badri DV, Zolla G, Bakker MG, Manter DK, Vivanco JM. Potential impact of soil microbiomes on the leaf metabolome and on herbivore feeding behavior. New Phytol. 2013;198:264-73.

48. Chaparro JM, Badri DV, Bakker MG, Sugiyama A, Manter DK, Vivanco JM. Root exudation of phytochemicals in Arabidopsis follows specific patterns 
that are developmentally programmed and correlate with soil microbial functions. PLoS One. 2013;8:e55731.

49. Tripathi KP, Singh B. The role of revegetation for rehabilitation of sodic soils in semiarid subtropical Forest. India Restor Ecol. 2005; https://doi.org/10.1111/j.1526-100X.2005.00005.x.

50. Ancona V, Grenni P, Caracciolo AB, Campanale C, Lenola MD, Rascio I. PlantAssisted Bioremediation: An Ecological Approach for Recovering Multicontaminated Areas. In: Lukac M, Grenni P, Gamboni M, editors. Soil biological communities and ecosystem resilience. Sustainability in plant and crop protection. Switzerland: Springer, Cham; 2017. p. 291-303.

51. Stock AM, Robinson VL, Goudreau PN. Two-component signal transduction. Annu Rev Biochem. 2000;69:183-215.

52. Held NA, Mcllvin MR, Moran DM, Laub MT, Saito MA. Unique patterns and biogeochemical relevance of two-component sensing in marine bacteria. mSystems. 2019; https://doi.org/10.1128/mSystems.00317-18.

53. Nunes-Da-Rocha U, Van-Overbeek L, Van-Elsas JD. Exploration of hitherto-uncultured bacteria from the rhizosphere. FEMS Microbiol Ecol. 2009;69:313-28

54. Kielak AM, Van-Veen JA, Kowalchuk GA. Comparative analysis of acidobacterial genomic fragments from terrestrial and aquatic metagenomic libraries, with emphasis on acidobacteria subdivision 6. App Environ Microb. 2010;76:6769-77.

55. Lee SH, Ka JO, Cho JC. Members of the phylum Acidobacteria are dominant and metabolically active in rhizosphere soil. FEMS Microbiol Lett. 2008;285:263-9.

56. Kielak AM, Cipriano MA, Kuramae EE. Acidobacteria strains from subdivision 1 act as plant growth-promoting bacteria. Arch Microbiol. 2016;198:987-93.

57. Singh BK, Munro S, Potts JM, Millard P. Influence of grass species and soil type on rhizosphere microbial community structure in grassland soils. Appl Soil Ecol. 2007;36:147-55.

58. Zhang YG, Cong J, Lu H, Li GL, Qu YY, Su XJ, et al. Community structure and elevational diversity patterns of soil Acidobacteria. J Environ Sci. 2014;26:1717-24.

59. Ikenaga M, Guevara R, Dean A, Pisani C, Boyer J. Changes in community structure of sediment bacteria along the Florida coastal everglades marshmangrove-seagrass salinity gradient. Microb Ecol. 2010;59:284-95.

60. Li M, Hong YG, Cao HL, Gu JD. Mangrove trees affect the community structure and distribution of anammox bacteria at an anthropogenicpolluted mangrove in the Pearl River Delta reflected by 16S rRNA and hydrazine oxidoreductase ( $\mathrm{HZO}$ ) encoding gene analyses. Ecotoxicology. 2011;20:1780-90.

61. Wu P, Xiong X, Xu Z, Lu C, Cheng H, Lyu X, et al. Bacterial communities in the rhizospheres of three mangrove tree species from Beilun estuary, China. PLoS One. 2016;11:e0164082.

62. Wyman M, Hodgson S, Bird C. Denitrifying Alphaproteobacteria from the Arabian Sea that express the gene (nosZ) encoding nitrous oxide reductase in oxic and sub-oxic waters. Appl Environ Microbiol. 2013;79:2670-81.

63. Oliveira V, Gomes NCM, Cleary DFR, Almeida A, Silva AMS, Simões MMQ, et al. Halophyte plant colonization as a driver of the composition of bacterial communities in salt marshes chronically exposed to oil hydrocarbons. FEMS Microbiol Ecol. 2014;90:647-62.

64. Coleman-Derr D, Desgarennes D, Fonseca-Garcia C, Gross S, Clingenpeel S, Woyke $T$, et al. Plant compartment and biogeography affect microbiome composition in cultivated and native Agave species. New Phytol. 2016;209:798-811.

65. Hu D, Cha G, Gao B. A Phylogenomic and molecular markers based analysis of the class Acidimicrobiia. Front Microbiol. 2018;15:9-987.

66. Klindworth A, Pruesse E, Schweer T, Peplies J, Quast C, Horn M, Glöckner FO. Evaluation of general $16 \mathrm{~S}$ ribosomal RNA gene PCR primers for classical and next-generation sequencing-based diversity studies. Nucleic Acids Res. 2013;41:e1.

67. Wang Y, Qian PY. Conservative fragments in bacterial 165 rRNA genes and primer design for 165 ribosomal DNA amplicons in metagenomic studies. PLoS One. 2009;4:e7401.

68. Caporaso JG, Kuczynski J, Stombaugh J, Bittinger K, Bushman FD, Costello EK, et al. QIIME allows analysis of high-throughput community sequencing data. Nat Methods. 2010;7:335-6.

69. Oksanen J, Blanchet FG, Friendly M, Kindt R, Legendre P, McGlinn D, et al. In: Vegan: Community Ecology Package. R package version 2.4-4. 2017. https://github.com/vegandevs/vegan.

70. Kassambara A. ggpubr: 'ggplot2'. Based Publication Ready Plots. R package version 0.2. 2018. https://CRAN.R-project.org/package $=$ ggpubr.
71. Langille MGI, Zaneveld J, Caporaso JG, McDonald D, Knights D, Reyes JA, et al. Predictive functional profiling of microbial communities using 16S rRNA marker gene sequences. Nat Biotechnol. 2013;31:814-21.

72. Chazdon RL, Chao A, Colwell RK, Lin SY, Norden N, Letcher SG, et al. A novel statistical method for classifying habitat generalists and specialists. Ecology. 2011;92:1332-43.

73. Kumar S, Stecher G, Tamura K. MEGA7: molecular evolutionary genetics analysis version 7.0 for bigger datasets. Mol Biol Evol. 2016;33:1870-4.

74. Letunic I, Bork P. Interactive tree of life $\mathbf{V} 2$ : online annotation and display of phylogenetic trees made easy. Nucleic Acids Res. 2011;39:475-8.

\section{Publisher's Note}

Springer Nature remains neutral with regard to jurisdictional claims in published maps and institutional affiliations.
Ready to submit your research? Choose BMC and benefit from:

- fast, convenient online submission

- thorough peer review by experienced researchers in your field

- rapid publication on acceptance

- support for research data, including large and complex data types

- gold Open Access which fosters wider collaboration and increased citations

- maximum visibility for your research: over $100 \mathrm{M}$ website views per year

At BMC, research is always in progress.

Learn more biomedcentral.com/submissions 